\title{
Evaluating Wrongness Constraints on Criminalisation
}

\author{
Adam R. Pearce ${ }^{1}[$
}

Accepted: 26 September 2020 / Published online: 30 September 2020

(c) The Author(s) 2020

\begin{abstract}
Some claim that criminalisation is morally permissible only when the conduct criminalised is morally wrong. This claim can be disambiguated into at least three principles which differ according to whether, and how, wrongness is dependent on details of the law: the strong constraint, the moderate constraint, and the weak constraint. In this paper I argue that the weak wrongness constraint is preferable to the strong and moderate constraints. That is, we should prefer the view that conduct criminalised must be morally wrong, but qualifying wrongness can depend on criminalising the conduct first. Further, I will show that my arguments in support of the weak wrongness constraint have wider implications. Favouring the weak wrongness constraint implies that condemning wrongs cannot be the only legitimate reason in favour of criminalisation. Those who think condemnation can justify criminalisation should be pluralists.
\end{abstract}

Keywords Criminalisation · Wrongness constraint · R. A. Duff · Victor Tadros • Legal moralism

The criminal justice system wields frightening state power. A criminal charge, let alone a conviction, can upend one's life. This power naturally raises the question of when making people liable to the criminal justice system is morally permissible. In other words, when is criminalisation justified? One partial answer to that question is to endorse a wrongness constraint. A wrongness constraint on criminalisation specifies that it is a necessary condition of morally permissible criminalisation that the conduct criminalised is morally wrong. ${ }^{1}$ It is a negative principle of criminalisation. It does not, as a positive principle would, give reason for criminalisation; instead

\footnotetext{
${ }^{1}$ All subsequent references to 'permissibility', 'wrongness' and 'wrongs' refer more precisely to moral permissibility, wrongness, and wrongs.
}

Adam R. Pearce

a.r.pearce@pgr.reading.ac.uk

1 University of Reading, Reading, UK 
it says that conduct cannot be criminalised, for any reason, if it is not wrong. In recent years the inclusion of a wrongness constraint in normative theories of criminalisation has been the subject of scrutiny with some authors rejecting the constraint entirely. $^{2}$ In response, some defences of a wrongness constraint have remained ambiguous between importantly different variants of a wrongness constraint. ${ }^{3}$ And although Anthony Duff's defence is attuned to different variants of a wrongness constraint, he defends only one variant consistent with his further views on criminalisation. ${ }^{4}$ Consequently, no comparative evaluation of three different wrongness constraints has been undertaken. The three variants-distinguished fully in section II-are: (i) the strong constraint, according to which permissibly criminalised conduct must be wrong independent of the details of the law (or, pre-legally wrong); (ii) the moderate constraint, according to which permissibly criminalised conduct must be wrong independent of details of criminal law, allowing wrongness dependent on regulation; and (iii) the weak constraint, according to which permissibly criminalised conduct must be wrong, allowing wrongness dependent on regulation and criminal law. In this article I conclude that the weak wrongness constraint is the most defensible variant. ${ }^{5}$

I evaluate three variants of the wrongness constraint because thinking about the wrongness constraint in isolation casts light on the broader theory of criminalisation we ought to endorse. Before now, a wrongness constraint has been treated as a downstream principle of criminalisation to be rendered consistent with the broader theory of criminalisation one endorses upstream. I suggest we reverse that flow of reasoning and see what follows. A wrongness constraint is an intuitive prima facie principle of criminalisation and so we have reason to see how its best interpretation

\footnotetext{
${ }^{2}$ Critics include: Vincent Chiao, Criminal Law in the Age of the Administrative State (New York, NY: Oxford University Press, 2018), 172-79; Andrew Cornford, "Rethinking the Wrongness Constraint on Criminalisation," Law and Philosophy 36, no. 6 (2017): 615-49, https://doi.org/10.1007/s10982-0179299-z; Victor Tadros, Wrongs and Crimes (New York, NY: Oxford University Press, 2016); and Edwards is indirectly critical of a wrongness constraint in the process of rejecting the view that justifications of punishment and criminalisation ought to be linked: James Edwards, "Criminalization without Punishment," Legal Theory 23, no. 2 (2017): 69-95, https://doi.org/10.1017/S1352325217000210.

3 A direct response to recent criticisms of the wrongness constraint can be found in: Douglas Husak, "Wrongs, Crimes, and Criminalization," Criminal Law and Philosophy 13, no. 3 (2019): 393-407, https ://doi.org/10.1007/s11572-017-9453-6; earlier defences of a wrongness constraint against anticipated objections can be found in: Douglas Husak, Overcriminalization (New York, NY: Oxford University Press, 2008), 72-77; and A. P. Simester and Andrew [Andreas] von Hirsch, Crimes, Harms, and Wrongs (Oxford: Hart, 2011), 22-27.

${ }^{4}$ Duff defends a wrongness constraint consistent with his expressivist theory of criminalisation. He responds directly to recent criticisms of a wrongness constraint in: R. A. Duff, The Realm of Criminal Law (New York, NY: Oxford University Press, 2018), 58-70 \& 318-20; and his earlier defences against anticipated objections can be found in: R. A. Duff, "Towards a Modest Legal Moralism," Criminal Law and Philosophy 8, no. 1 (2014): 217-35, https://doi.org/10.1007/s11572-012-9191-8; R. A. Duff, Answering for Crime: Responsibility and Liability in the Criminal Law (Oxford: Hart, 2007), 166-74; and R. A. Duff, "Crime, Prohibition, and Punishment," Journal of Applied Philosophy 19, no. 2 (2002): 102-6, https://doi.org/10.1111/1468-5930.00207.

5 It is not my aim to defend a wrongness constraint against total sceptics. See works cited in notes 3 and 4 for that. My aim is to see what wrongness constraint is preferable provided there should be one at all.
} 
impacts broader theories of criminalisation. In Rawlsian parlance, we need also to consider the impact of a wrongness constraint on broader theories-not just vice versa-to attain reflective equilibrium. ${ }^{6}$

To be clear, 'broader' theories of criminalisation give an account of the nature of criminal law (what does it mean to criminalise?) and provide conditions that make criminalisation permissible (why criminalise and when?). Michael Moore's retributive theory is explicitly broad in scope and serves an illustrative purpose here; it claims (1) the distinctive function of the criminal law is delivering retributive justice (and so what it is to criminalise is to make something liable to a retributive state response), and (2) the only ground for permissible criminalisation is to give offenders the punishment they deserve for wrongdoing. ${ }^{7}$ Contrastingly, a wrongness constraint is narrower in scope; all it says is (roughly) whatever criminalisation is, and whatever the right reasons for criminalising might be, conduct should not be criminalised unless it is wrong. Given its narrowness of scope, a wrongness constraint is compatible with many broader theories of criminalisation. Analogously, a democratic principle of free and fair elections constrains how societies may be governed, but it is compatible with several broader ideologies of the organisation of society: socialist, social democrat, libertarian, and so on. But as a democratic principle of free and fair elections is not consistent with an authoritarian organisation of society, I will go on to show that the weak wrongness constraint is inconsistent with one available broader theory of criminalisation.

I will come to two conclusions. First, I argue that the weak wrongness constraint is most defensible. The weak wrongness constraint preserves all weighty reasons to endorse a wrongness constraint. The weak wrongness constraint cannot preserve all reasons for endorsing a wrongness constraint, but this is preferable because the remaining reasons are not very compelling and alternatives to the weak constraint are subject to troubling counterexamples unless they make implausible factual claims. Second, those who claim that moral condemnation can justify criminalisation should admit that more than condemnation may justify criminalisation. The second conclusion is an implication of the first because the weak constraint admits of plausible cases where condemnation cannot be a reason to criminalise plausibly criminalised conduct, which is inconsistent with views which make condemnation a required reason for criminalisation.

I will proceed as follows. In section I, I will give four reasons for endorsing a wrongness constraint. These motivate examining a wrongness constraint and clarifying them is important for the arguments which follow. In section II I will distinguish the three variants of a wrongness constraint in more detail. Section III will then undertake the bulk of the work: arguing the weak constraint is most defensible. Finally, section IV will detail why preferring the weak constraint rules out theories which require condemnation as a reason for criminalisation.

\footnotetext{
${ }^{6}$ Rawls details the method of reflective equilibrium in: John Rawls, A Theory of Justice, Rev. ed. (New York, NY: Oxford University Press, 1999), 18-19 \& 42-45.

7 Michael S. Moore, Placing Blame (New York, NY: Oxford University Press, 1997).
} 


\section{Why Defend a Wrongness Constraint?}

In this section I give four reasons for endorsing a wrongness constraint. ${ }^{8}$ The first reason arises from the following argument: criminal conviction typically morally condemns (and according to some theorists should morally condemn) ${ }^{9}$ the criminal actions of the convicted, and when conduct is not wrong moral condemnation is morally impermissible because it is inapt. ${ }^{10}$ On one view, inapt condemnation is wrong just because condemnation is not a fitting response to permissible conduct. The idea here is that ensuring fittingness of condemnation is a basic moral requirement. Contrast this with other views which claim that inapt condemnation is derivatively wrong because it is just one instance (among others) of violating a more basic moral requirement. For example, perhaps condemning permissible conduct is wrong because it violates basic moral prohibitions on lying or deception, or for consequentialist reasons concerning the expected effect on the condemned or the expected effect on the law as a respectable institution. ${ }^{11}$ Whatever the substance of the argument, support for the claim that inapt condemnation is wrong provides reason to endorse a wrongness constraint.

A second argument in support of a wrongness constraint concerns punishment. Criminalisation renders those convicted liable to punishment, and punishment of non-wrongdoers is presumptively unjust. ${ }^{12}$ The charge of injustice can be supported by citing some non-consequentialist norm or right; supported by consequentialist reasoning citing the diminishing effectiveness of a system of punishment which punishes permissible conduct; or supported by some other, less obvious reasoning. Again, if one is moved by the claim that punishment for permissible conduct is unjust, and is convinced by an explanation of some sort, then one has more reason to defend a wrongness constraint. Of course, criminalisation creates liability to punishment (and condemnation) rather than entailing punishment. Were criminalisation to entail punishment, there would be strong reason to endorse a wrongness constraint in order to avoid unjust punishment. Conversely, without any realistic prospect of punishment there would be no reason to endorse a wrongness constraint

\footnotetext{
${ }^{8}$ It is unsurprising these reasons are numerous because a wrongness constraint is widely endorsed. In addition to those already noted (see notes $3 \& 4$ above) those who support a wrongness constraint include: Larry Alexander, Kimberly Kessler Ferzan, and Stephen J. Morse, Crime and Culpability (New York, NY: Cambridge University Press, 2009), 6-7; Moore, Placing Blame, 661; Joel Feinberg, Harm To Others (New York, NY: Oxford University Press, 1984), 36.

9 Classic accounts of the positive role of condemnation in criminalisation and punishment are: Andrew [Andreas] von Hirsch, Censure and Sanctions (New York, NY: Oxford University Press, 1996), https ://doi.org/10.1093/acprof:oso/9780198262411.001.0001; R. A. Duff, Punishment, Communication, and Community (New York, NY: Oxford University Press, 2000); and retributive theories generally, such as Moore's, would likely welcome condemnation as part of a deserved response to wrongdoing: Moore, Placing Blame.

10 Detailed explanations of this view can be found in: Husak, "Wrongs, Crimes, and Criminalization," 401-4; and Cornford, "Rethinking the Wrongness Constraint on Criminalisation," 629-633.

11 Cornford considers each of these reasons in more detail: "Rethinking the Wrongness Constraint on Criminalisation," 629-633.

12 Again, for more on this claim see: Husak, "Wrongs, Crimes, and Criminalization," 401; and Cornford, "Rethinking the Wrongness Constraint on Criminalisation," 622-625.
} 
in order to avoid unjust punishment. Since the reality is somewhere in between these extremes, liability to punishment provides at least some reason to endorse a wrongness constraint. But I acknowledge that even partial moratoriums on punishment could undermine reason to endorse a wrongness constraint on all criminalisation. If all property offences remained crimes but were no longer punished, then there would be no reason to endorse a wrongness constraint on all criminalisation in order to avoid unjust punishment, but there would be reason for criminalisation of nonproperty offences.

It might be argued that preventing unjust punishment is no further reason to endorse a wrongness constraint as unjust punishment and inapt condemnation are concerning for the same reason - that criminalisation itself, and subsequent punishment, are condemnatory. If you take the view that punishment must be condemnatory then you might think these two arguments are the same (or at least considerably linked). Nevertheless, it is possible to imagine a legal system which sentences the convicted to hardships without condemning; and we might think these hardships, being especially burdensome, require special justification-justification that wrongness can provide. ${ }^{13}$ Moreover, one might think that punishment is (or should be) condemnatory but that the hardships of punishment are to be justified independently from the condemnatory intent. ${ }^{14}$ But the relationship between these first two reasons for a wrongness constraint, whatever it is, is unimportant here because all variants of a wrongness constraint are consistent with both.

A third argument for a wrongness constraint holds that respecting personal autonomy requires limiting the scope of criminalisation to wrongs. ${ }^{15}$ This argument might be understood in at least two ways. It could be understood as an absolute prohibition on infringing valuable autonomy, but criminalisation of wrongs is permissible because freedom to do wrong is not a valuable form of autonomy. ${ }^{16}$ Alternatively, the autonomy argument could be understood as a presumption against infringing autonomy which is only overridden by appropriately criminalised wrongs. According to either of these views, criminalisation must be restricted to wrongs in order to adequately value autonomy.

As stressed at the outset, a wrongness constraint is narrow in scope; it says nothing about the nature of the criminal law as a broader theory would, only that wrongness is a necessary condition of permissible criminalisation. The wrongness constraint is also a negative principle of criminalisation, since it specifies what ought not be criminalised, distinct from a positive theory which specifies the reasons

\footnotetext{
13 Hart's famous definition of punishment does not include condemnation as a necessary condition: $\mathrm{H}$. L. A. Hart, Punishment and Responsibility (London: Oxford University Press, 1968), 4-5.

14 This is Husak's view, see: Douglas Husak, "What Do Criminals Deserve?," in Legal, Moral, and Metaphysical Truths: The Philosophy of Michael S. Moore, ed. Kimberly Kessler Ferzan and Stephen J. Morse (New York, NY: Oxford University Press, 2016), 49-62, https://doi.org/10.1093/acprof:oso/97801 98703242.003.0004.

15 As before, detail in: Husak, "Wrongs, Crimes, and Criminalization," 404; and Cornford, "Rethinking the Wrongness Constraint on Criminalisation," 625-629.

16 Those who believe there is no value to freedom to do wrong include: Tadros, Wrongs and Crimes; and Joseph Raz, The Morality of Freedom (Oxford: Clarendon, 1988).
} 
which justify criminalisation. The wrongness constraint is consistent with a host of different positive reasons in favour of criminalisation. A wrongness constraint may be required, however, by a positive theory of criminalisation. The fourth reason to endorse a wrongness constraint is that a wrongness constraint is required by an influential positive theory of criminalisation. For 'positive legal moralists', like Duff, ${ }^{17}$ there is reason to criminalise conduct only when that conduct is (publicly) wrong and so should be appropriately condemned. Rather than continue to refer to legal moralism, call reasons to condemn 'expressivist reasons' and call theories which require expressivist reasons to justify criminalisation 'expressivist theories'. ${ }^{18}$ Expressivist theories require a wrongness constraint to be satisfied because the case for criminalising the conduct is otherwise defeated. ${ }^{19}$ The case is defeated because when conduct is not wrong, there is no expressivist reason to criminalise that conduct. As a consequence, endorsing an expressivist theory gives conclusive reason to endorse a wrongness constraint. This means that expressivists, or at least anyone who wishes to keep an expressivist theory available, have a fourth reason to maintain a wrongness constraint.

\section{Distinguishing Strong, Moderate, and Weak Wrongness Constraints}

Victor Tadros distinguishes a strong and weak wrongness constraint. ${ }^{20}$ In fact, I think there are three different variants of a wrongness constraint. I recharacterise his strong constraint as a moderate constraint and add a variant stronger still. The three principles of my taxonomy are introduced separately as appropriate in what follows.

In order to understand the distinction between the three different variants of the wrongness constraint, it is useful to refer to the distinction between crimes malum in se and crimes malum prohibitum. Mala in se offences (offences 'wrong in themselves') proscribe conduct which is wrong independent of the details of the

\footnotetext{
17 Duff outlines and defends his theory of positive legal moralism first in: Duff, "Towards a Modest Legal Moralism"; and most recently in: Duff, The Realm of Criminal Law.

18 NB: The term 'expressivist' is usually reserved for theories of punishment. I do not use it in such a restricted way. I use it as 'expressivist reasons' is more economical than 'positive legal moralist reasons'. It also allows for the distinction between expressivist and desert-based versions of positive legal moralism. See note 19.

19 Duff's theory is expressivist as I have used the term as it maintains that criminalisation must be motivated by condemning public wrongs in the appropriate public forum, i.e. the courts. Explicitly: "[w]e have reason to criminalize a type of conduct if, and only if, it constitutes a public wrong." Duff, The Realm of Criminal Law, 232; Moore's legal moralism, although grounded in desert rather than condemnation (and is therefore not expressivist, since the conditions for satisfying desert and condemnation could be quite different), would also have a similar indirect reason to endorse a wrongness constraint. This is because Moore's legal moralism holds that the only legitimate reason for criminalisation is to give offenders their just deserts for culpable wrongdoing. So, if a wrongness constraint is not satisfied, there is no reason to criminalise according to Moore: Placing Blame, 662.

20 Victor Tadros, "Wrongness and Criminalization," in The Routledge Companion to Philosophy of Law, ed. Andrei Marmor (New York, NY: Routledge, 2012), 158, https://doi.org/10.4324/9780203124352. ch11.
} 
law. For example, killing (without very good justification) is wrong independent of whether it is, given the legal situation, the criminal offence of murder. By contrast, mala prohibita offences (offences 'wrong because prohibited') supposedly require details of the law to render the underlying conduct wrong. The example of a malum prohibitum I will proceed with, like any, is controversial. Views differ on the precise content of moral duties such that, even if we can agree the example is morally wrong, we may disagree about whether it is wrong dependent on, or independent of, law. If my example is unconvincing, swap it for another you find convincing. It is the structure of the example, not the detail, which is important. My example is as follows: it is unlikely that it is wrong, independent of law, to pay marginally less than would be required by a legal minimum wage; but it would be wrong to undercut a legal minimum wage. One reason why undercutting a minimum wage is wrong is that a minimum wage seeks to improve living standards by improving wages at the bottom of the scale. Undercutting the minimum wage is wrong because it frustrates the project of improving living standards both consequentially and symbolically. Absent the minimum wage law, however, it would not be possible to frustrate the project of improving living standards by paying a given wage because either there is no organised effort to raise living standards (as in an extreme laissez-faire economy) or because the means of raising living standards does not depend on conformity to a minimum wage (as could be true of a Universal Basic Income scheme). Of course, a given token of the offence could be malum in se-e.g. exploitatively low wages-but the offence category overall is best labelled malum prohibitum because all offence tokens are at least malum prohibitum. With this clarifying example we can characterise the distinction between mala in se and mala prohibita as a distinction between wrongs independent of, or dependent on, details of the law.

Now consider the strong wrongness constraint:

Strong wrongness constraint: it is a necessary condition of morally permissible criminalisation that the conduct proscribed is morally wrong independent of law.

The strong wrongness constraint disqualifies any genuine mala prohibita conduct from permissible criminalisation because mala prohibita offences, by definition, are wrong dependent on details of the law.

Alternatively, the moderate constraint is as follows:

Moderate wrongness constraint: it is a necessary condition of morally permissible criminalisation that the conduct proscribed is morally wrong independent of criminalisation.

The moderate constraint is more permissive, than the strong wrongness constraint, about how permissibly criminalisable conduct may be wrong. The moderate wrongness constraint rules out criminalisation when criminalisation itself is a necessary condition of the wrongness of the conduct in question. If regulation is sufficient to make conduct wrong-not the additional threat of criminal proceeding and sanctions - then the moderate wrongness constraint is satisfied. But when criminalisation 
itself is a necessary condition of the wrongness of conduct, the moderate wrongness constraint holds that criminalisation is impermissible. The moderate wrongness constraint relies upon being able to reasonably clearly distinguish criminal and non-criminal law. While there may be no bright line to draw between criminal laws and regulations, a rough distinction suffices here. Criminal law implicates criminal procedure (with its special attendant rights, standard of proof, etc.) and punishment, whereas regulation does not implicate criminal procedure and punishment-often because the law is effectively enforced with civil penalties (such as moderate fines) and government agency oversight (such as the Financial Conduct Authority). ${ }^{21}$

Lastly, consider the weak wrongness constraint:

Weak wrongness constraint: it is a necessary condition of morally permissible criminalisation that the conduct proscribed is morally wrong, but criminalisation may be a necessary condition of the wrongness of the conduct.

The weak wrongness constraint is most permissive, of the three constraints, about how permissibly criminalisable conduct may be wrong. On this view wrongness may be conditional on criminalisation itself. What the weak constraint does still rule out, however, is the criminalisation of morally permissible conduct. Of course, if there is a content-independent moral duty to obey the law because it is authoritative law, then the weak constraint would constrain nothing. Few contemporaries defend a contentindependent duty to obey the law, however, so few are likely to level this complaint. ${ }^{22}$ That said, Thomas Christiano and others argue that we have a content-independent duty to obey the law when that law is appropriately democratically produced. ${ }^{23}$ This view, though, is not as troubling for the weak wrongness constraint as it might be.

One reason democratic authority is not so troubling is that the democratic procedures required to generate content-independent obligation are very demanding, so it is unlikely a weak wrongness constraint is redundant in practice. Another reason is that we might doubt that the duty to obey democratically authorised law is absolute. Conclusively establishing that the duty is not absolute would lead me astray, but it will be enough to motivate discussing the weak wrongness constraint by raising doubt. Doubt arises when we ask how democratic authorisation creates a moral duty to obey especially ineffective and moralistic criminal law. For example, criminalisation of drug possession is plainly ineffective, ${ }^{24}$ and drug possession is (at least) arguably morally

\footnotetext{
${ }^{21}$ Glanville Williams' widely discussed and criticised definition of criminal law defines criminal law as implicating criminal procedure: Glanville Williams, "The Definition of Crime," Current Legal Problems 8, no. 1 (1955): 107-30, https://doi.org/10.1093/clp/8.1.107. Its circularity makes it an unhelpful definition but it does help distinguish criminal from non-criminal law for my purposes.

${ }^{22}$ For a review of the literature see: William A. Edmundson, "State of the Art: The Duty to Obey the Law," Legal Theory 10, no. 4 (2004), https://doi.org/10.1017/S1352325204040236.

${ }^{23}$ Thomas Christiano, "The Authority of Democracy," Journal of Political Philosophy 12, no. 3 (2004): 266-90, https://doi.org/10.1111/j.1467-9760.2004.00200.x; Daniel Viehoff, "Democratic Equality and Political Authority," Philosophy \& Public Affairs 42, no. 4 (2014): 337-75, https://doi.org/10.1111/ papa.12036.

${ }^{24}$ There is widespread criticism of drug policy among criminologists. An international report by The Global Commisson on Drug Policy is illustratively damning of existing criminal regulation of drug possession, see: The Global Commission on Drug Policy, “The War on Drugs," 2011.
} 
permissible. ${ }^{25}$ Even supposing criminalising drug possession is democratically authorised, it is difficult to believe that it is morally wrong to disobey an ineffective and moralistic criminal law although there might still be prudential reasons to obey it. I assume laws which fail badly enough in their own terms generate doubts about a content-independent duty to obey the law without much comment. But by moralistic laws, I mean laws which enforce a mainstream norm in society (e.g. drug use should be banned) which is disputed by some other reasonable citizens (e.g. personal drug use is my prerogative), and cannot be justified to reasonable citizens who disagree in terms they should accept (e.g. reduction of harm does not justify banning moderate possession for personal use). In Rawlsian parlance, moralistic laws are not justified with appeal to 'public reasons' acceptable to an 'overlapping consensus' of the population. ${ }^{26}$ This distinguishes objectionable moralistic laws from laws which proscribe moral wrongs (as a wrongness constraint requires). The complaint isn't that moralistic laws invoke moral claims, the complaint is that moralistic laws invoke moral claims inconsistent with public reason which is unjust (assuming some liberal commitments). When the injustice is on balance worse than failing to respect democratic authorisation then authorisation fails to bind, offending becomes permissible, and the offence is inconsistent with a wrongness constraint. ${ }^{27}$ Therefore, if these doubts about ineffective and moralistic laws are plausible, then a weak wrongness constraint still bites because it disqualifies criminalising drug possession (or equivalently ineffective and moralistic prohibitions).

\section{Why the Weak Constraint is Most Defensible}

With three versions of the constraint distinguished, I now argue that the weak constraint is most defensible. Recall the strong wrongness constraint: 'it is a necessary condition of morally permissible criminalisation that the conduct proscribed is morally wrong independent of law.' According to the strong wrongness constraint, if mala prohibita exist then their criminalisation is impermissible. This is because, by definition, mala prohibita conduct is wrong dependent on law. If a defender of the strong wrongness constraint is also to argue that many offences typically understood as mala prohibita are permissibly criminalised, then they will seek to deny these offences are mala prohibita. Although radical, this position is not immediately and obviously implausible.

It is not immediately implausible because law does not make apparent mala prohibita conduct wrong, as a literal understanding of the Latin would indicate. The law is not alchemy. It does not fundamentally change rights to wrongs like turning base metals to gold. Law is individually insufficient to make conduct wrong, even though

\footnotetext{
25 A convincing moral case for the legalisation of possession is made in: Douglas Husak, Legalize This! The Case for Decriminalizing Drugs (London: Verso, 2002).

26 See: John Rawls, Political Liberalism, Expand. ed (New York, NY: Columbia University Press, 2005).

27 For a recent defence of balancing justice with democratic authority see: Zofia Stemplowska and Adam Swift, "Dethroning Democratic Legitimacy," in Oxford Studies in Political Philosophy, ed. David Sobel, Peter Vallentyne, and Steven Wall, vol. 4 (New York, NY: Oxford University Press, 2018), 3-27.
} 
it can generate duties to act in particular ways, because the law must act in combination with pre-legal moral duties to make conduct wrong. Since there is no plausibly relevant moral duty, the law cannot make 'admiring the view' wrong, for example. Sensible mala prohibita offences make plausible connections between previously ambiguous or unrelated acts and pre-existing moral duties. ${ }^{28}$ One route to defending the strong wrongness constraint, then, is to emphasise the connection to pre-existing moral duties.

"It's hard to believe," Susan Dimock writes, "that anyone thinks such conduct is not wrong unless it's criminalized: that placing the safety of other road users in peril, damaging the environment, and making or selling products unfit for consumption would not be wrong unless criminalized." ${ }^{29}$ Dimock's sentiment is surely right, broadly speaking. There clearly is something wrong with this sort of behaviour prelegally, even though it appears to depend on details of the law. For example, damaging the environment is pre-legally wrong. Nevertheless, it is the details which are more complex. Whether disposing of household waste is damaging to the environment is dependent on how and where I dispose of it. Fly-tipping is damaging but disposing of waste in a regulated site with strict provisions for preventing subsequent pollution is not. And fly-tipping just is disposing of waste outside of regulated sites. So, whether disposing of waste is wrong is dependent on details of the law. But that is not to say that criminalisation has made damaging the environment wrong. There was always a pre-legal reason not to damage the environment, it is just that law can generate duties to act in particular ways which are only comprehensible given legislation. ${ }^{30}$

Noting the relationship of law to pre-legal reasons is not sufficient to defend the strong wrongness constraint, however. The defender of the strong wrongness constraint - if they are not to disqualify all mala prohibita-must make a further claim that all apparent mala prohibita violate pre-legal duties. This unusual claim must be made since wrongs permissibly criminalised according to the strong wrongness constraint cannot depend on details of the law. To see why this claim is unusual recall the example of paying below minimum wage. It is plausible we have pre-legal reasons not to undermine attempts to raise living standards, but this does not give us a pre-legal duty to pay a minimum wage because the minimum wage is a legal construct. We have the specific duty in virtue of the specific provision of a minimum

\footnotetext{
${ }^{28}$ One way of understanding this connection is to invoke Kant's distinction between perfect and imperfect duties. On this picture, the law converts pre-legal imperfect duties without concrete action prescriptions (to aid raising living standards, say) into perfect duties with concrete action prescriptions (to pay a minimum wage). This probably isn't the only way of understanding the phenomenon, but it seems to me like a helpful one. I'd like to thank an anonymous reviewer for this suggestion.

29 Susan Dimock, "The Malum Prohibitum-Malum in Se Distinction and the Wrongfulness Constraint on Criminalization," Dialogue 55, no. 1 (2016): 14, https://doi.org/10.1017/S0012217316000275; see also Tadros, who quickly narrows his discussion down to special cases after recognising that many apparent mala prohibita offences can be described as pre-legally wrongful: Tadros, "Wrongness and Criminalization," 166-67.

30 This is not a novel point. Joseph Raz outlines this connection because his service conception of authority relies on a relationship between pre-legal moral reasons and subsequent moral obligations given law. Joseph Raz, “Authority and Justification,” Philosophy \& Public Affairs 14, no. 1 (1985): 3-29.
} 
wage in law. We have no pre-legal duty to pay a minimum wage because without the law there is no minimum wage and so either no attempt to raise living standards at all or some other attempt to which precise wage rates are irrelevant. It is natural, then, that we say the law is a dependent detail of wrongs malum prohibitum. ${ }^{31}$ The strong wrongness constraint seems committed to denying this.

The problem with relying on the claim that mala prohibita are not what they seem is that we want principles to regulate the world as we find it and come to plausible conclusions. Ultimately it matters much more whether the principle comes to plausible conclusions but ideally principles also come to plausible conclusions in a recognisable way, and so don't appear to distort the relevant facts. Further, I assume that widely recognisable reasoning is especially important for principles, like principles of criminalisation, which regulate state intervention in our lives. If, as is plausible, the state owes us good justification for its interventions in our lives, it would be best if they offer justification to us in a widely recognisable way.

Alternatively, a defender of the strong wrongness constraint might be content to disqualify all mala prohibita. In which case, the defender of the strong wrongness constraint faces a dilemma. Either they are landed with a suspicious claim that all permissible criminal offences violate pre-legal duties (and deny dependence on the law), or they are required to reject several prima facie plausible criminal offences. To be clear, it is not obvious whether Dimock is stuck with the unusual claim that mala prohibita violate pre-legal duties or the claim that mala prohibita are rightly disqualified. Dimock claims that either laws are read as mala prohibita, in which case they are unjust, or laws are read as implicating pre-legal duties, in which case they are just but no longer mala prohibita. ${ }^{32}$ Dimock therefore picks up on the dilemma I present, but rather than address it Dimock instead concludes that the ordinary conceptual understanding of malum prohibitum is mistaken. A different understanding might be correct, conceptually speaking. Since even the most obvious mala in se rely on some legal stipulations - the offence of murder stipulates a maximum span of time between cause and death, for instance-perhaps the distinction is best understood as a difference in degree rather than kind. ${ }^{33}$ Some offences are more mala in se, others more mala prohibita, but every offence has elements of each. But reinterpreting mala prohibita in this way just amplifies the problem for the strong constraint. If the difference is a difference in degree, and every offence has a malum prohibitum component, then the strong wrongness constraint either disqualifies all criminal offences or makes suspicious claims about all criminal offences. Highlighting that all (reasonable) mala prohibita offences also have a malum in se component does not rescue the strong constraint either since this renders the strong constraint

\footnotetext{
31 In effect, this is just to restate Raz's rejection of the "no-difference thesis." Raz claims that just because authoritative law is grounded in pre-legal reasons, this does not mean that the law itself makes no difference to our reasons for action: ibid., 15-18.

32 Dimock, "The Malum Prohibitum-Malum in Se Distinction and the Wrongfulness Constraint on Criminalization," 15-17.

33 This view is attributable to Stuart Green, see: "Why It's a Crime to Tear the Tag off a Mattress: Overcriminalization and the Moral Content of Regulatory Offenses," Emory Law Journal 46, no. 4 (1997): 1533-1615. I'd like to thank an anonymous reviewer for prompting me to discuss this view.
} 
contradictory: mala prohibita both satisfy and fail it. Consequently, reinterpretation is a dead end for defending the strong constraint. In summary, finding that the strong constraint cannot avoid implausibly claiming that mala prohibita are not what they seem, else implausibly disqualify all mala prohibita offences, we might move to firmer ground by endorsing the moderate wrongness constraint instead.

Recall that, according to a moderate wrongness constraint, criminalisation is permissible so long as criminal law is not involved in making the conduct wrong. For example, it is permissible to criminalise tax evasion if the mere existence of a legal tax system makes evasion wrong. But it is not permissible to criminalise conduct for which criminalisation is a necessary condition of wrongness. It is plausible occasions of the latter case-conduct wrong only because it is criminalised-which present problems for the moderate constraint (and the strong constraint by extension).

Victor Tadros presents the problem in question by way of the following hypothetical case:

Possession of a knife in a public place may be wrong. But it may be wrong only if enough other people comply with the prohibition on knife possession. Were many people to carry knives, possession of a knife in a public place would be justified to enhance personal security. The appropriate security threshold may be reached only if knife possession is criminalized. Mere regulation of knife possession, where the regulation is not backed up by a threat of punishment, may be insufficient to render public knife possession wrong. Once enough people comply with the law prohibiting public knife possession, it becomes wrong to possess a knife. The dangers that public knife possession imposes on others, as well as the fear that knife possession may cause harm to citizens would, in that case outweigh any benefits to the person who possesses the knife. ${ }^{34}$

Tadros' example describes a scenario where possession of a knife is wrong only once criminalised. Criminalisation is thus impermissible according to the strong and moderate wrongness constraints. Without an adequate reply to this kind of case, the strong and moderate wrongness constraints would be implausible. Lack of a reply is implausible because I presume that such cases are not fiction and that they implicate important and plausible criminal proscriptions (like weapons possession) and not trivialities. $^{35}$

Duff offers a response to Tadros' case. Duff argues that Tadros' knife example is a malum in se dressed up as a malum prohibitum given a misleading action description. ${ }^{36}$ Insofar as we describe the criminalised act as 'knife possession' generally, it appears that criminalisation affects the permissibility of knife possession as Tadros describes. But this is a disputable action description of the conduct proscribed. A competing claim holds that it is a more granular action description

\footnotetext{
34 Tadros, "Wrongness and Criminalization," 169.

35 Of course, these assumptions might turn out to be factually wrong, but Tadros' case is certainly a possibility. And even if these cases are fictional, it is still a theoretical problem since these are the sort of problem that we would like a suitably complete theory to answer.

36 The argument in text follows Duff, The Realm of Criminal Law, 60-61.
} 
which is criminalised, 'non-self-defensive knife possession', and non-self-defensive knife possession is malum in se. It is wrong even if the intention is (mistakenly) selfdefensive because possession is not reasonably factually justified on self-defensive grounds. ${ }^{37}$ Moreover, the granular action description is more accurate in practice since criminal offences are subject to general defences like self-defence so it is only non-self-defensive possession which is criminalised de facto. Duff's reply renders Tadros' case consistent with both the strong and moderate wrongness constraints.

The telling shortcoming of Duff's appeal to granular action descriptions is that it does not work for a case where the offence cannot be re-interpreted as malum in se. Here is such a case. It could be wrong to possess a knife even when appropriately justified by self-defence prior to criminalisation, and when possession continues to have self-defensive reasons in its favour after criminalisation, because possession is wrong on balance conditionally on the existence of criminal law. This will be the case, at least temporarily, in Tadros' knife possession example. For simplicity, we imagine the criminal prohibition of knife possession in Tadros' case working instantaneously: once possession is a crime, the rate of possession is reduced sufficiently to render all possession non-self-defensive. But the much more likely outcome is that the rate of possession will trend downwards following criminalisation and only after some time is it true that all cases of possession are not supported by self-defensive reasons. Consequently, for some time after criminalisation possessors have selfdefensive reasons for possession. Criminalisation, however, can make a difference to the balance of reasons for possession-and therefore make possession unjustified on balance despite self-defensive reasons - and it does so by introducing a collective action solution from which it would be unfair to defect. In order for the criminal law to have its expected effect-i.e. in order for the rate of possession to be reduced by the threat of criminal sanctions - there will need to be first-movers which set the expected effect in train. Those first-movers will need to overlook or overrule the fact that disarming is not in their immediate defensive interest because it is in the long-term defensive interest of all. Disarming, then, is a collective action problem where the solution is criminal law which threatens sanctions for non-compliance. And non-compliance in the face of legitimate collective action problem solutions is commonly thought to be wrong because free riding violates a principle of fairness. ${ }^{38}$

The example from Tadros, adjusted to account for a lag in securing sufficient compliance, still provides a case where conduct (knife possession) is justified precriminally (because self-defence justifies possession in the absence of counterbalancing reasons) but unjustified post-criminally (because, although agents still have self-defensive reasons to possess, they now have weightier reason to avoid free-riding). But now notice how Duff's reply to Tadros does not help answer the adjusted example. Duff's claim was that the conduct criminalised in Tadros' example is not possession simpliciter, but instead non-self-defensive knife possession and, because

\footnotetext{
37 Of course, in this scenario subsequent guilt would depend upon whether intention is a required mens rea. But the underlying conduct, the actus reus, is wrong according to the granular action description.

38 For a very detailed explanation and defence of this view see: Garrett Cullity, "Moral Free Riding," Philosophy \& Public Affairs 24, no. 1 (1995): 3-34, https://doi.org/10.1111/j.1088-4963.1995.tb00020.x.
} 
non-self-defensive knife possession is malum in se, the example is consistent with the moderate (and strong) wrongness constraint(s). This move cannot be made for the adjusted example, however, because the adjusted example demonstrates one of two possibilities - neither consistent with the moderate constraint. Either 'non-selfdefensive knife possession' is not always malum in se because at least one instance of it is only wrong once criminalised-i.e. possession, which despite self-defensive reasons in its favour, is not justified by self-defence because self-defence is outweighed by reasons of fairness conditional on the existence of the criminal law. Or, possession is no longer a case of non-self-defensive knife possession (even though possessors still have self-defensive reasons) and better described some other way, such as 'unjustified knife possession', which still admits of at least one malum prohibitum case. In short, the wrong cannot be recast as malum in se, or wrong dependently on regulation, so it cannot be made consistent with the strong or moderate wrongness constraints.

Let me now respond to some objections to the preceding argument. First, in order for the example to do the work I have attributed to it, it needs to be true that the unfairness of defecting from a collective action solution outweighs the reason agents have to possess a knife to defend themselves. Given the gravity of self-defence and the scope of permissions it provides-sometimes even killing in self-defenceit might seem that the example rests on an implausible balancing of reasons. Put another way: if self-defence is such a strong reason that it can sometimes justify killing, why can't it justify acting unfairly? Part of the problem with this objection is that it does not adequately reflect the variable strength of self-defensive reasons. While imminent threats to life may justify deadly retaliatory force, the strength of my reason to defend myself diminishes as the severity of the threat decreases and the remoteness of the threat increases. When we consider the threat to the public of widespread knife possession it should be noted that while the severity of the threat is serious - serious injury, perhaps death - the threat is relatively remote, in the sense that there is an appreciable, but low probability that I will be attacked. This suggests that the strength of my reasons to defend myself from widespread knife possession, by myself possessing a knife as a deterrent, might not obviously outweigh my reasons to avoid unfairly defecting from a collective action solution. And so when we also note that I am not being asked to give up my interest in self-defence permanently by complying with the ban on possessing a knife-instead being asked to temporarily disarm with a view to widespread compliance and, therefore, widespread defence-it is much less obvious that possessing a knife can be justified by self-defence in defiance of a reliable solution for widespread defence.

Turning now to a second objection, if all that is required to make possession wrong despite self-defensive reasons is a collective action solution, then why can't that collective action solution be provided by regulation $?^{39}$ Remember that according to the moderate constraint (but not the strong constraint) permissibly criminalised conduct may be wrong dependent on details of regulation. Once regulation stipulates a collective action solution, defection from the solution can then be

39 I'd like to thank an anonymous reviewer for raising this objection. 
criminalised consistently with the moderate wrongness constraint because defection is wrong. The reason this objection fails is that it does not appreciate that criminal law is necessary to the success of the collective action solution. Note that Tadros stipulates only the threat of criminal sanctions is enough to predictably reduce the incidence of knife possession to eliminate justifications of self-defence. Criminalisation, then, is the only means to make the collective action solution effective. Plausibly, only effective collective action solutions generate obligations to comply out of fairness - at least, only solutions we have reasons to believe will be effective given the available evidence obligate-so mere regulation banning knife possession cannot make it wrong to possess a knife because non-criminal regulation is not enough to obligate (and make defection wrong). Only effective collective action solutions obligate because it is implausible that ineffective 'solutions' obligate. Consider the following, obviously ineffective, solution. Imagine the dominant religious community advises that all believers pray for would-be knife possessors to have the strength to disarm and publicly announces that would-be possessors' spirits will be liable to sanctions in the afterlife. Even if we grant that God sometimes answers prayers and that we have spirits liable to consequences in an afterlife, the religious intervention won't solve the problem. It won't solve the problem because no one believes God always intervenes and consequences in the afterlife will often weigh unfavourably (even for believers) against present and tangible threats of bodily harm. I take it to be clear that despite their efforts, we do not treat the religious community and the few disarmers they convince unfairly by choosing not to disarm since they fail to provide the benefit (mutual defence) for which our sacrifices (disarming) are asked. Only when the expected benefit can be (to some minimal extent) secured are we required to make our personal sacrifices. So, in the present case, knife possession cannot be made pre-criminally wrong by mere regulation because mere regulation does not obligate; mere regulation does not obligate because it does not create an effective collective action solution. Consequently, this second objection fails.

A final objection denies that the wrong cannot be recast as malum in se, but instead of adjusting to a more granular action description, this objection takes the opposite route and maintains that the offence violates a broad pre-legal duty 'to comply with reasonable effective collective action solutions when they arise. ${ }^{40}$ Notice that this objection reveals the similarity between the problems posed to the strong and moderate constraints. The problems for both constraints are collective action problems which require legal solutions. The difference is that the problem case for the moderate constraint is considerably more complex than problem cases for the strong constraint since the problem for the moderate constraint needs to exclude the effects of regulation. Also, resorting to the claim that there is a pre-legal duty to accept reasonable effective collective action solutions hangs the prospects of the strong and moderate wrongness constraints together because the purported duty is pre-legal, not just pre-criminal, and so rescues both the strong and moderate wrongness constraints if successful. The upshot of their prospects hanging together, however, is that their prospects are similarly problematic. Resorting to a pre-legal

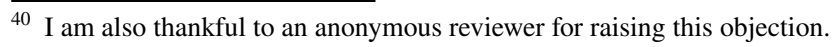


duty to accept reasonable effective collective action solutions when they arise produces the same problem I raised earlier against the strong constraint - that it appears to distort the relevant facts. We have a case of an offence which appears to clearly depend on criminalisation to make it wrong, only for an objection to deny that we have to describe the world this way. I can't see a reason why this objection must fail, but as I outlined earlier it is at least a little costly and certainly unnecessary.

It is costly because it would be better if principles came to plausible conclusions in conjunction with a recognisable picture of the relevant facts, and this is especially so for principles which play some role in justifying to us when the state may and may not intervene in our lives. And it is unnecessary because we can constrain the scope of the criminal law to wrongs by adopting the weak constraint without appearing to distort the relevant facts. Finally, it is unclear why we should have a pre-legal duty 'to accept reasonable effective collective action solutions when they arise', which just happens to save the strong and moderate wrongness constraints rather than a duty, for instance, 'to support just institutions. ${ }^{41}$ A duty to support just institutions justifies criminalisation in the knife possession case above but need not save the strong and moderate constraints since it could allow that just institutions act to alter the precise content of our duties via legislation, criminal and non-criminal. Again, I can't see a decisive reason why we ought to reject a duty to accept reasonable effective collective action solutions when they arise, but nor can I see a reason to prefer it to a duty to support just institutions either.

If I am right about what the case above shows and my responses to the preceding objections, then the strong and moderate constraints cannot costlessly account for the wrong because the wrong appears to straightforwardly depend upon details of the criminal law. The problem generally that this case demonstrates is that the strong and moderate constraints cannot account for all cases of prima facie plausible criminalisation without making implausible factual claims. As a result, we have found that Duff's reply to Tadros' problem does not resolve the difficulty which that problem raises.

The preceding argument shows that maintaining the strong or moderate constraints is problematic. The weak constraint, by contrast, is not similarly problematic because, according to the weak wrongness constraint, criminalisation and wrongness can come together. Recall: 'it is a necessary condition of morally permissible criminalisation that the conduct proscribed is morally wrong, but criminalisation may be a necessary condition of the wrongness of the conduct.' The considerations so far, then, count in favour of the weak wrongness constraint. In the remainder of this section I argue that the weak wrongness constraint is most defensible because its attendant drawback is less troubling.

The central criticism of the weak wrongness constraint is that it is not consistent with an expressivist theory of criminalisation whereas the strong and moderate variants are. Recall from section I that a wrongness constraint can be a corollary of expressivist theories of criminalisation, because wrongness is a necessary condition of having expressivist reason (reasons grounded in condemnation) to criminalise.

${ }_{41}$ I have in mind here Rawls' natural duty of justice from: Rawls, A Theory of Justice, 99. 
As the weak constraint admits of cases where conduct is not wrong before its criminalisation, however, an expressivist theory cannot endorse the weak constraint. This is because there can be no expressivist reason to criminalise non-wrongful conduct. According to expressivism, wrongness is what makes conduct criminalisable; so, if the conduct is not wrong before criminalisation then there is no property which makes it criminalisable when the offence is created. And if there is no property which makes conduct criminalisable then (obviously enough) it should not be criminalised. If expressivism did allow criminalisation in order to create condemnable conduct, that would be a departure from the initially plausible view that wrongs ought to be condemned, in favour of the implausible view that we should generate wrongs so that we can condemn them. ${ }^{42}$ That's the rather more serious penal equivalent of laughing at your own jokes.

However, it remains the case when endorsing the weak constraint that all conduct criminalised is apt for condemnation and its punishment just, ${ }^{43}$ and that autonomy is not (unreasonably) limited - three of four reasons for endorsing a wrongness constraint that I outlined in section I. I take a moment to note this as it is not clear from the existing literature. Duff defends the moderate constraint in pursuit of maintaining an expressivist theory and so need not consider the virtues of the weak constraint. ${ }^{44}$ At the same time, those who endorse a weak constraint do so without noting that they do so at so little comparative cost. ${ }^{45}$ It would not be unusual for some positive reasons to drop out as the wrongness constraint becomes weaker: for example, consider how the reasons for adopting a speed limit on the roads weaken as the speed constraint is weakened (i.e. as the speed limit is increased the safety provided reduces). But while one reason does drop out as the wrongness constraint is weakened, most remain.

Inconsistency with expressivism is a drawback for the weak constraint, though, as it means the weak constraint can call upon fewer reasons in its favour in comparison with the strong and moderate constraints. Still, I argue that the weak constraint is preferable to the strong and moderate constraints because this drawback is acceptable, unlike the drawback of the strong and moderate constraints. Inconsistency with expressivist reasons in some cases is acceptable because the value of maintaining these reasons in those cases is minimal. Imagine a minor licence infraction. In this case, the wrong in the minor licence infraction must be small by definition-but this may not rule out criminalisation. Criminalisation may well be the best way of enforcing the licensing scheme and the licensing scheme may be very beneficial. Perhaps the threat of punishment is required because civil penalties are insufficient

\footnotetext{
42 "It would be very odd indeed to criminalize conduct in order to make it wrong... Retributivists believe that the suffering of wrongdoers is good in itself. But surely they don't believe that its goodness can motivate us to bring about more wrongdoing so that we can pursure more of this good." Tadros, "Wrongness and Criminalization," 171. These claims are true of a non-retributive expressivist view too.

43 That is, if punishment can be just at all. But it will be easier to argue it is just when the conduct is wrongful than when permissible.

44 To be clear, Duff defends what I characterise as the moderate constraint. Duff, following Tadros, does not distinguish a variant stronger still and so claims to defend a 'strong' constraint. See note 4.

45 See note 3 .
} 
deterrents. For example, if a company is required to obtain a licence for some business venture but the maximum proportionate civil fine for non-compliance is less than the expected return on investment, then civil enforcement will be inadequate. When considering this case, it is implausible to claim that condemning the wrong done gives us the decisive reason to criminalise. It cannot play this role as the wrong is minimal; too minimal to render criminalisation proportionate given the predictable negative consequences of criminalisation. ${ }^{46}$ It is therefore hard to maintain that expressivist reasons are absolutely necessary in all cases because in cases like these they are of so little importance. ${ }^{47}$ And since they are unlikely to be absolutely necessary, we should not be against admitting as much.

So, I conclude the weak constraint is most defensible. The weak wrongness constraint has one fewer reason in its favour, but the additional value of that reason is minimal. Contrastingly, the strong and moderate constraints are vulnerable to counterexamples of plausible offences they disqualify or else resort to implausible factual claims about the dependence of wrongness on criminal law and regulation.

\section{Preferring the Weak Constraint Rules Out Expressivist Theories of Criminalisation}

As a final matter, I want to draw out how an argument for finding the weak constraint most defensible is also an argument that expressivists should endorse a pluralist account of the reasons capable of justifying criminalisation. Expressivists cannot consistently claim that the weak wrongness constraint is most plausible, and that expressivist reasons are required for criminalisation to be permissible. This is because the weak wrongness constraint admits of cases where conduct is permissibly criminalised despite the lack of expressivist reasons. Expressivist reasons are lacking in those cases because the conduct is wrong only once criminalised, and so the wrong can give us no reason for criminalisation ex ante. So, if we come to a view about which broader theory of criminalisation to endorse after we have considered which of three wrongness constraints is most plausible- the ordering I suggested at the outset we should consider-then we have reason to reject views which claim that expressivist reasons to criminalise are a necessary condition of permissible criminalisation. ${ }^{48}$ To put it another way, if you're an expressivist you shouldn't be solely expressivist.

\footnotetext{
${ }^{46}$ Brownlee lists nearly a dozen predictable negative consequences of criminalisation generally: Kimberley Brownlee, "Justifying Punishment: A Response to Douglas Husak," Criminal Law and Philosophy 2, no. 2 (2008): 127-28, https://doi.org/10.1007/s11572-008-9046-5.

47 Remember that condemnation need not drop out of the picture entirely once the conduct has been criminalised for non-expressivist reasons. It is perfectly consistent with criminalising a minor licence infraction because this tends to best enforce the licencing system that the post-criminal wrong committed in breaking the licence is condemned after the fact. This is explained in: Simester and von Hirsch, Crimes, Harms, and Wrongs, 27.

${ }^{48}$ By extension, this also gives reason to reject Moore's view. Since the weak wrongness constraint admits of cases where there is no wrong prior to criminalisation, it is inconsistent with an exclusively retributive positive theory of criminalisation. See note 19.
} 
On this matter I agree with Tadros. ${ }^{49}$ But my arguments have built on Tadros' to substantiate this conclusion further. First, I have shown that Duff's reply does not address all the problems that are raised by the cases Tadros presses against it, something Tadros has not yet done. Second, I reach the same conclusion from a weaker premise. I do not claim that the moderate wrongness constraint is false (as Tadros does). Rather, I claim that even if the moderate constraint is defensible, the weak constraint is most defensible and that gives sufficient reason to rule out solely expressivist views in reflective equilibrium.

Admittedly, expressivists might deny that a plausible wrongness constraint could ever be support for (or rule out) some broader theory. At least at present, however, that claim is under-motivated. The claim under consideration, and the received wisdom, merely assumes that selecting a broader theory is a prior theoretical matter with no supporting argument. Although it is important to begin with a big picture - an idea of what we take the criminal law to be, what we therefore take it to be doing, and what we think it ought to be doing in comparison-we should not rule out refining that bigger picture in line with compelling independent principles. So, we've got to begin to think about how we weigh the importance of a plausible wrongness constraint and a plausible broader theory. At present, it is unclear why (if at all) we should prefer to maintain expressivist theories of criminalisation at the expense of the best wrongness constraint on criminalisation. Before we settle which considerations are more important, we cannot assume that preserving broader theories of criminalisation should take priority over the best available interpretation of the wrongness constraint.

\section{Conclusion}

I have argued that the weak wrongness constraint is preferable to the strong and moderate constraints. This comparative claim has been occluded by sympathetic discussions of the constraint undertaken before now. Further, I have demonstrated that my arguments in support of the weak wrongness constraint have wider implications. When considered a matter theoretically upstream, favouring the weak wrongness constraint implies that expressivists should admit additional reasons capable of justifying criminalisation.

Acknowledgements I am grateful for very helpful comments from a number of people: to two anonymous reviewers for Criminal Law and Philosophy, to Luke Elson and Rob Jubb for written comments on multiple earlier drafts of this paper, to Jamie Draper and Livia Luzzatto for written comments on an earlier draft, and to an audience at the University of Reading. This paper was made possible by a Doctoral Scholarship from the Leverhulme Trust for which I am also very thankful.

Open Access This article is licensed under a Creative Commons Attribution 4.0 International License, which permits use, sharing, adaptation, distribution and reproduction in any medium or format, as long as you give appropriate credit to the original author(s) and the source, provide a link to the Creative Commons licence, and indicate if changes were made. The images or other third party material in this article are included in the article's Creative Commons licence, unless indicated otherwise in a credit line to the

49 Tadros, "Wrongness and Criminalization." 
material. If material is not included in the article's Creative Commons licence and your intended use is not permitted by statutory regulation or exceeds the permitted use, you will need to obtain permission directly from the copyright holder. To view a copy of this licence, visit http://creativecommons.org/licen ses/by/4.0/.

Publisher's Note Springer Nature remains neutral with regard to jurisdictional claims in published maps and institutional affiliations. 